\title{
Assessment of weight gain during pregnancy in general prenatal care services in Brazil
}

\author{
Avaliação de ganho ponderal intra-gestacional \\ em serviços de assistência pré-natal no Brasil
}

Luciana Bertoldi Nucci 1

Bruce Bartholow Duncan 1

Sotero Serrate Mengue 1

Leandro Branchtein 1

Maria Inês Schmidt 1

Eni Teresinha Fleck 2

\footnotetext{
1 Departamento de Medicina Social, Faculdade de Medicina, Universidade Federal do Rio Grande do Sul. Av. Ramiro Barcelos 2600, sala 414, Porto Alegre, RS 90035-003, Brasil. 2 Universidade de Fortaleza. Rua Dr. José Lourenço 1500, sala 501, Bloco A, Fortaleza, CE 60115-281, Brasil.
}

Abstract Obesity is an emerging major health risk for women around the world. In this regard, little attention has been given to pregnancy, a moment of risk not only for major weight gain in these women, but also for macrosomia in their offspring. The objective of this study is to evaluate weight gain during pregnancy. Data pertains to a cohort of pregnant women attending general prenatal care clinics in six state capitals in Brazil, from 1991 to 1995. We studied women aged 20 years and over with singl eton pregnanci es and no diagnosis of diabetes outsi de pregnancy, enrolled at approximately 20 - 28 weeks of gestation. According to the Institute of Medicine criteria, $38 \%$ ( $95 \% \mathrm{Cl}: 36-40 \%)$ of the women studied gained less and $29 \%$ (95\% $\mathrm{Cl}: 28-31 \%)$ had more than the recommended total weight gain. These proportions vary according to prepregnancy nutritional status. Given the increasing epidemic of obesity, the high prevalence of overweight and obesity in Brazilian women prior to pregnancy, and the lack of achievement of recommended weight gain during pregnancy, more effective means of managing weight gain during pregnancy are necessary.

Key words Obesity; Pregnancy; Weight Gain; Body Mass Index

Resumo Obesidade é um fator de risco para a saúde da mulher que vem crescendo em muitos países. A esse respeito, pouca atenção real tem sido dada à gravidez, um momento de risco não apenas pelo elevado ganho de peso das mulheres, mas também pela macrossomia em seus recém-nasci dos. O obj etivo deste estudo é avaliar o ganho de peso durante a gravidez. Trata-se de um estudo de coorte de mulheres atendi das em serviços de pré-natal geral do Sistema único de Saúde, em seis capitais brasileiras, entre 1991 e 1995. Participaram da pesquisa mulheres com 20 ou mais anos de idade, sem diagnóstico de diabetes fora da gravidez, com aproximadamente 21-28 semanas de gestação, sem gestações múlti plas. De acordo com o critério do Institute of Medicine, 38\% (IC95\%: 36-40\%) das mulheres estudadas ganharam abaixo e 29\% (IC95\%: 28$31 \%)$ acima do ganho total recomendado. Essas proporções variam de acordo com as categorias de peso pré-gravídico. Dado o aumento na epidemia de obesidade, a al ta prevalência de sobrepeso e obesidade prévi os à gravidez em mulheres brasileiras e a falta de controle do ganho de peso recomendado durante a gestação, pode-se ver que mei os mais eficientes de conduzir o ganho de peso durantea gestação são necessários.

Palavras-chave Obesi dade; Gravidez; Ganho de Peso; Índice de Massa Corporal 
Introduction

Obesity, which confers increased risk for several diseases - among them diabetes and coronary heart disease, is an increasingly common condition. According to the World Health Organization (WHO, 1998), this increase can be characterized as a pandemia of major public health concern. Data concerning overweight and obesity in recently published studies show over one-third of the adult population in many countries to be overweight (Al-Isa, 1998; Allison et al., 1997; Flegal et al., 1998; Foreyt \& Poston, 1998; Grol et al., 1997; Rozowski \& Arteaga, 1997). Although the prevalence of obesity is greater in more developed countries, it has increased dramatically in several developing countries over recent decades (WHO, 1998).

Using WHO weight status criteria, defined as a body mass index (BMI) of $<18.5 \mathrm{~kg} / \mathrm{m}^{2}$ for underweight, $\geq 25.0 \mathrm{~kg} / \mathrm{m}^{2}$ and $<30 \mathrm{~kg} / \mathrm{m}^{2}$ for pre-obesity, and $\geq 30.0 \mathrm{~kg} / \mathrm{m}^{2}$ for obesity $(\mathrm{NIH} /$ NHLBI, 1998; WHO, 1998), the frequency of obesity among Brazilian women, for example, increased over 60\% from 1975 to 1989 (Monteiro et al., 1995; Sichieri et al., 1994). A more recent survey in the Northeast and Southeast regions of the country confirms a continued increase in obesity among Brazilian women of reproductive age especially among the economically less privileged, suggesting that the frequency of obesity continues to increase (Monteiro et al., 2000).

The upper limit of the ideal weight (or BMI) for a woman who wants to become pregnant and the maximum ideal weight gain during pregnancy have received relatively little study (IOM , 1990; Rosso, 1985). As the mother is the only source of fetal nutrition, traditional concern has focussed upon being underweight for pre-pregnancy and low weight gain during pregnancy (Cnattingius et al., 1998). In consonance with these concerns, recommended gestational weight gain nearly doubled from the 1930 's through the 1980 's - from $6.8 \mathrm{~kg}$ to a range of $11.4 \mathrm{~kg}$ to $15.9 \mathrm{~kg}$. However, socioeconomic development and food supplementation programs have reduced the incidence of intrauterine growth retardation, commonly evaluated by low birth weight for gestational age (IOM, 1990). Thus, more recently, concern of excessive gestational weight gain has received increasing attention.

Brazil is a very heterogeneous country. Problems of obesity and excessive gestational weight gain co-exist with low nutrition and insufficient gestational weight gain. Though both conditions are associated with problems of great public health concern, the frequency of insufficient and excessive gain among Brazilian pregnant women has yet to be reported in a large, multi-center study.

The objective of this study is to evaluate gestational weight gain in women attending pre-natal clinics of the national health system in different state capitals of Brazil.

\section{M ethods}

Data from a cohort study of consecutive pregnant women are presented. The study was conducted in general prenatal care clinics (Sistema Único de Saúde - SUS) in six state capitals of Brazil, from 1991 to 1995 . A total of 5,564 women aged 20 years and over, approximately $20-28$ weeks pregnant with no diagnosis of diabetes outside pregnancy were interviewed and had anthropometric measures obtained. Of this total, 73 women were excluded due to no record of measured weight after week 20 of gestation, 248 due to missing information necessary to calculate pre-pregnancy BMI and 51 women because of multiple gestation. Data on prepregnancy BMI thus pertain to 5,192 women.

All additional pregnancy data were obtained through chart review, which was not available for many women, principally due to the facts that their pre-natal visits and deliveries occurred in other services or that they returned infrequently for further pre-natal care. For calculations pertaining to weight gain, $1,123(22 \%)$ women were thus excluded for not having a recorded weight beyond the $28^{\text {th }}$ gestational week. For calculations of total weight gain, 987 (19\%) additional women were excluded for lack of sufficient measurements to estimate 3rd trimester gain or lack of information on gestational age at birth, leaving 3,082 for analyses.

At enrollment, a standardized questionnaire was completed including information on prepregnancy weight. Weight and height were measured in duplicate according to a standard protocol. The interviewer defined ethnicity according to the color of the participant's skin.

Gestational age (in complete weeks) was defined according to hierarchical criteria based on four parameters - ultrasound, estimate of gestational age by physical examination at birth (Capurro et al., 1978), last menstrual period and uterine height at enrollment - and their compatibility (agreement within two weeks). Gestational age was calculated based on ultrasound before week 26 for $52 \%$ of the sample; on a reported last menstrual period consistent 
with neonatal examination or uterine height for 22\%; and on an ultrasound after week 26 consistent with neonatal examination or last menstrual period for $14 \%$. In the remaining $12 \%$ of pregnancies, gestational age was based on just one criterion (either uterine height, neonatal examination, ultrasound after week 26 or last menstrual period).

Pre-pregnancy weight was self-reported. Pre-pregnancy weight status was classified according to the WHO (1998) recommendations, and, to permit comparisons with recommended gains, also according to similar, but not identical criteria of the Institute of Medicine (IOM, 1990). Additional prenatal weights were extracted from clinic records.

Mean BMI at each week of gestational age was calculated using weights recorded for all women having clinic visits at that gestational age. Trimesters were defined as first (less than 14 complete weeks), second (14-27 complete weeks) and third ( 28 weeks through delivery).

Average weekly weight gain for second and third trimesters was estimated using the difference between the first and the last weights recorded during that trimester, divided by the number of weeks separating the two observations. Trimester weekly weight gain was calculated provided that weights spaced at least four complete weeks apart were available. Weekly weight gain over the joint period of the second and third trimesters was estimated similarly, provided that an interval of at least 10 complete weeks between measurements was available.

Given the small numbers of recorded weights during first trimester, which occurred prior to study enrollment, the following approaches were used to estimate first trimester weekly weight gain, using the pre-pregnancy weight referred by the patient.

If a first trimester weight was available, 1st trimester gain per week was estimated as:

\begin{tabular}{c} 
Weight at last recorded 1st trimester \\
visit - prepregnancy weight \\
\hline Gestational age at last recorded \\
1st trimester weight
\end{tabular}

If no first trimester weight was available, then 1st trimester gain per week was estimated as:

(Weight at 1st recording - pre-pregnancy weight) - [ (Gestational age at 1st recording 14) $\times$ 2nd trimester weekly gain ] 14

Total weight gain was estimated as last recorded weight minus pre-pregnancy weight.
As the last recorded weight was frequently measured at a prenatal visit, if gestational age at last recorded weight was less than gestational age at delivery, then total weight gain was adjusted to estimate total gain at delivery as:

(Last recorded weight - pre-pregnancy weight) + [weekly 3rd trimester weight gain $x$ (gestational age at delivery - gestational age at last weight)]

Total weight gain for trimester was estimated multiplying specific trimester weekly weight gain by the number of weeks during trimester (14 for first and second trimesters and 12 for the third trimester). The three trimester total weight gains were added to estimate the gain for gestation of 40 weeks length.

Analyses were performed using SAS software package (SAS Institute, 1998). Analyses are descriptive in nature, including frequency distributions, frequency distribution curves, percentiles and mean ( \pm standard deviation), whenever appropriate. Statistical tests for means (ANOVA) and proportions (Qui-square) were used to compare groups.

Local institutional ethic committees approved the study protocol at each center.

\section{Results}

Table 1 presents descriptive statistics for the 3,082 women for whom total weight gain to delivery could be calculated and for those 2,110 who could not. Frequency distributions of the characteristics presented are generally similar between the two groups, the only important difference being the somewhat unequal degree of follow-up at the different centers. Pre-pregnancy weight status was quite similar between these two groups of women (for example 6.6\% of each were obese at conception). Mean estimated weight gain from conception through enrollment was $6.5 \mathrm{~kg}( \pm 4.9)$ for all 5,192 women, and $6.4 \mathrm{~kg}( \pm 5.0)$ for the 3,082 women followed through delivery.

Figure 1 shows frequency distribution curves for BMI by WHO criteria before pregnancy and at examination, between approximately weeks 20 and 28. Both curves show slight positive skew indicative of the relatively increased frequency of high BMI, compared to what would be expected from a Gaussian distribution. As expected from the increased pregnancy related gain in lean and fat body mass, the distribution of BMI values obtained during the weeks 20-28 of pregnancy is shifted to the right, compared to that of pre-pregnancy values. WHO standard cut points for weight status outside pregnancy 
Characteristics of adult pregnant women in the cohort study, 1991 to 1995.

\begin{tabular}{|c|c|c|c|c|c|}
\hline \multirow[t]{2}{*}{ Characteristics } & \multicolumn{2}{|c|}{$\begin{array}{l}\text { Those followed through delivery } \\
\qquad(\mathrm{n}=3,082)\end{array}$} & \multicolumn{2}{|c|}{$\begin{array}{l}\text { Excluded } \\
(\mathrm{n}=2,110)\end{array}$} & \\
\hline & $n^{*}$ & $\%$ & $n^{*}$ & $\%$ & \\
\hline \multicolumn{6}{|l|}{ Study center } \\
\hline Porto Alegre & 686 & 22.3 & 364 & 17.3 & \\
\hline São Paulo & 618 & 20.1 & 598 & 28.3 & \\
\hline Rio de J aneiro & 404 & 13.1 & 132 & 6.3 & \\
\hline Salvador & 519 & 16.8 & 343 & 16.3 & \\
\hline Fortaleza & 719 & 23.3 & 372 & 17.6 & \\
\hline Manaus & 136 & 4.4 & 301 & 14.3 & $p<0.001$ \\
\hline \multicolumn{6}{|l|}{ Skin color } \\
\hline White & 1,416 & 46.1 & 927 & 44.2 & \\
\hline Mixed & 1,242 & 40.4 & 892 & 42.5 & \\
\hline Black & 413 & 13.5 & 279 & 13.3 & $p=0.311$ \\
\hline \multicolumn{6}{|l|}{ Pre-pregnancy weight status (WHO) } \\
\hline Underweight $\left(\mathrm{BM} \mathrm{I}<18.5 \mathrm{~kg} / \mathrm{m}^{2}\right)$ & 172 & 5.6 & 132 & 6.3 & \\
\hline Normal $\left(18.5 \mathrm{~kg} / \mathrm{m}^{2} \leq \mathrm{BMI}<25.0 \mathrm{~kg} / \mathrm{m}^{2}\right)$ & 2,020 & 65.5 & 1,438 & 68.2 & \\
\hline Pre-obesity $\left(25.0 \mathrm{~kg} / \mathrm{m}^{2} \leq \mathrm{BMI}<30 \mathrm{~kg} / \mathrm{m}^{2}\right)$ & 686 & 22.3 & 402 & 19.1 & \\
\hline O besity (BMI $\left.\geq 30.0 \mathrm{~kg} / \mathrm{m}^{2}\right)$ & 204 & 6.6 & 138 & 6.5 & $p=0.038$ \\
\hline \multicolumn{6}{|l|}{ Education } \\
\hline$<8$ years & 1,328 & 43.2 & 916 & 43.5 & \\
\hline $8-11$ years & 1,466 & 47.7 & 956 & 45.4 & \\
\hline$>11$ years & 278 & 9.1 & 235 & 11.2 & $p=0.029$ \\
\hline
\end{tabular}

* The small variation in category totals results from missing information relating to the characteristic in question. $\mathrm{BMI}=$ Body Mass Index; WHO = World Health O rganization.

are indicated to highlight the limitations of their use for the assessment of weight status during pregnancy.

Figure 2 shows for each gestational week the $\mathrm{BMI}$ value of percentiles equivalent to the WHO pre-pregnancy BMI cut points for underweight (here percentile 6.2), pre-obesity (percentile 73.1) and obese (percentile 93.6) women for this sample. In general, one sees very modest increases of BMI during the first trimester, but it clearly increases thereafter. Although greater variation in the distribution of weight in obese women creates some irregularity, in general, all curves follow a similar pattern.

The average rate of weight gain during pregnancy in the first trimester was $0.18 \mathrm{~kg} /$ week $( \pm 0.35)$. Obese and pre-obese women tended to gain less weight, $0.14 \mathrm{~kg} /$ week ( \pm 0.40 ) and $0.09 \mathrm{~kg} /$ week $( \pm 0.41)$. During the $2 \mathrm{nd}$ and 3 rd trimesters, weight gains were $0.43 \mathrm{~kg} /$ week $( \pm 0.27)$ and $0.40 \mathrm{~kg} /$ week $( \pm 0.30)$, respectively, with a slight tendency for lower gains in the pre-obese and obese women. As the rates of weight gain were similar in these two trimesters, they can be expressed jointly as an overall rate of $0.41 \mathrm{~kg} /$ week $( \pm 0.19), 0.39 \mathrm{~kg} /$ week $( \pm 0.21)$ for pre-obese women and $0.32 \mathrm{~kg} /$ week $( \pm 0.22)$ for obese.

Estimated weight gain during the first trimester was $2.5 \mathrm{~kg}( \pm 5.0)$ as shown in Table 2. Obese and overweight women had lesser gains ( $p<0.001$ ). During 2nd and 3rd trimesters, weight gains were $6.0 \mathrm{~kg}( \pm 3.7)$ and $4.8 \mathrm{~kg}( \pm$ $3.6)$, respectively. The total gain over 2 nd and 3 rd trimesters was $10.6 \mathrm{~kg}( \pm 5.1)$. As expected, obese and overweight women showed lower weight gains ( $p<0.001$ ).

Total weight gain over all trimesters was $12.7 \mathrm{~kg}( \pm 6.2)$ with lower weight gains for the overweight $(11.5 \mathrm{~kg} \pm 6.5)$ and obese $(9.2 \mathrm{~kg} \pm$ 8.4) and higher gains for the underweight $(14.2 \mathrm{~kg} \pm 5.5)$ women ( $p<0.001)$. Comparison of weight gains observed with those recommended by the Institute of Medicine in 1990 shows that for overweight women (the Institute of Medicine category roughly equivalent to 
pre-obesity, as defined by the WHO) the mean is at the upper level of the recommended range and for obese women the mean gain is also high compared to the Institute of Medicine recommendations.

Table 3 shows the frequency of women who gained less than, within or more than the range recommended by Institute of Medicine, according to pre-pregnancy weight categories. An upper limit of $11.5 \mathrm{~kg}$, equal to that for overweight women (Cogswell et al., 1995) was chosen for obese women for these calculations, as the Institute of Medicine did not define an upper limit for this class of women. Overall, less than one-third of women had weight gains within the recommended range. Gains outside this range were especially common for women who were obese pre-pregnancy. Only $22 \%$ of these women had weight gain within the desired range. Excessive weight gain was particularly high in the overweight women; inadequate gain in the lean $(p<0.001)$.

Reanalysis of the fractions of women achieving weight gain goals, using WHO BMI cut points instead of those of the Institute of Medicine to define baseline nutritional status categories, resulted in similar percentages (data not shown).

\section{Discussion}

We found high pre-pregnancy frequencies of pre-obesity and obesity (28\% together) in comparison with underweight (6\%) among Brazilian women receiving pre-natal care through the national health system in major cities. The national health system provides care for the approximately $75 \%$ of Brazilians, without employment related or private medical coverage (Faquim, 1999). This sample of Brazilian women presents a picture being increasingly reported for women around the world, that of high prevalence of pre-obesity and obesity (Benicio et al., 1995; Monteiro et al., 2000; Sichieri et al., 1994), in an era in which obesity is increasingly a major factor for future health risks in women. Further, we found that recommended weight gain during pregnancy is infrequently achieved, especially in obese and overweight women, categories in which we estimate that less than $30 \%$ achieved recommended gains.

Given the importance of obesity, and the frequent clinical uncertainty about reported pre-pregnancy weight, it is convenient to try to estimate baseline obesity status from weight at the initial prenatal visit. Figure 2 permits this estimation of WHO nutritional classification
Figure 1

Distribution of body mass index $\left(\mathrm{kg} / \mathrm{m}^{2}\right)$ before and during pregnancy (at study enrollment) in women aged 20 to 48 . World Health Organization standard cut points for outside of pregnancy are indicated for underweight, pre-obesity and obesity.
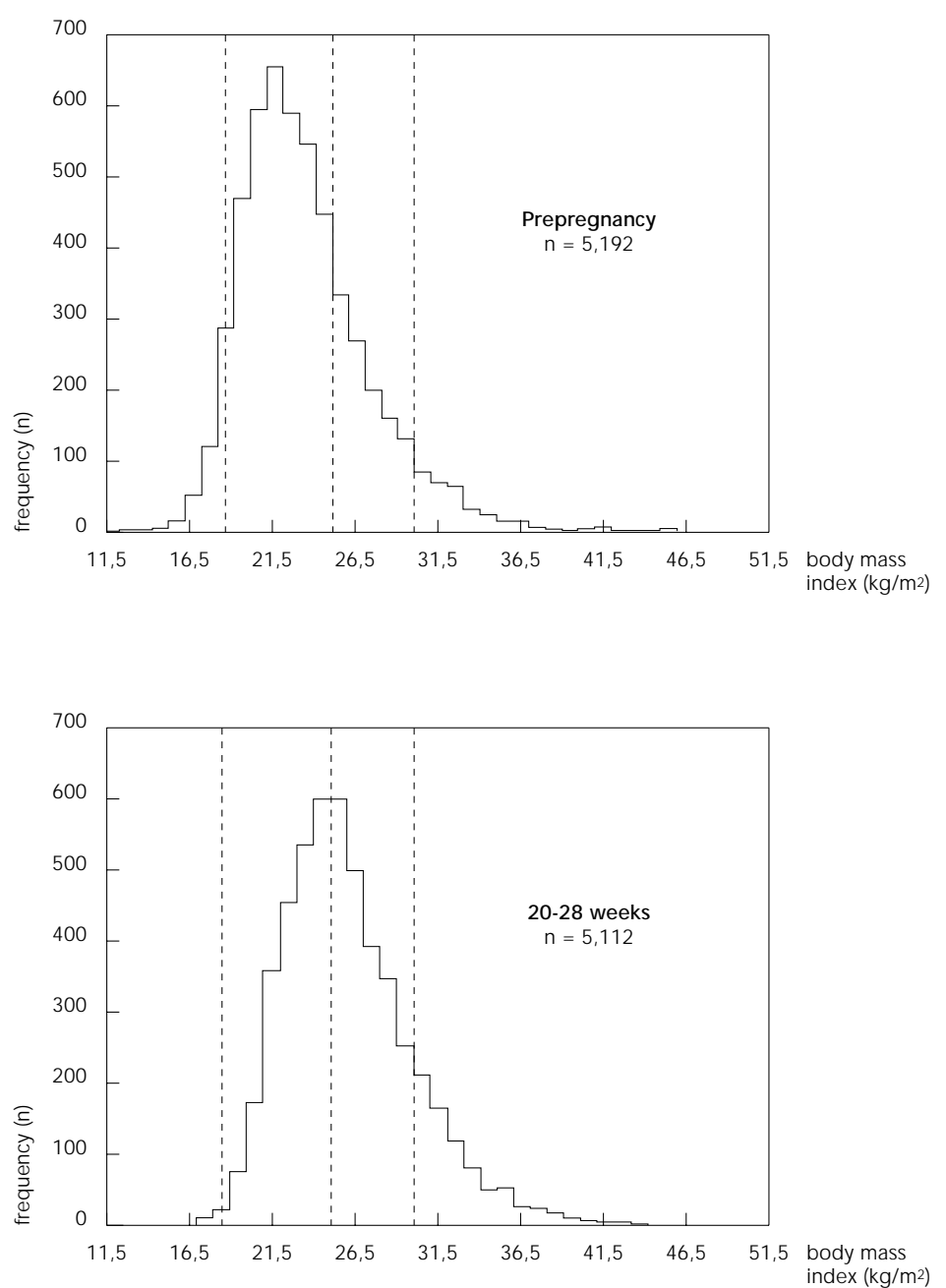

category in pregnant women at different gestational ages. This chart thus may be of use for estimating baseline nutritional class, and thus recommended weight gain, for women without reliable pre-pregnancy weight. For example, a women with $\mathrm{BMI}$ of $26.0 \mathrm{~kg} / \mathrm{m}^{2}$ at 20 weeks gestation, though pre-obese by standard criteria, presents weight within the normal range, as evaluated using Figure 2.

Few other studies have documented the current distribution of pre-pregnancy weights and weight gain during pregnancy. Of note is one studying women attending public clinics in Los Angeles, California from 1983 to 1986 
Figure 2

Body mass index (BMI) according to gestational age for pregnant women at percentiles equivalent to those of World Health O rganization prepregnancy BMI cut points for underweight $\left(18.5 \mathrm{~kg} / \mathrm{m}^{2}\right)$, pre-obese $\left(25 \mathrm{~kg} / \mathrm{m}^{2}\right)$ and obesity $\left(30 \mathrm{~kg} / \mathrm{m}^{2}\right)$, and the $50^{\text {th }}$ percentile.

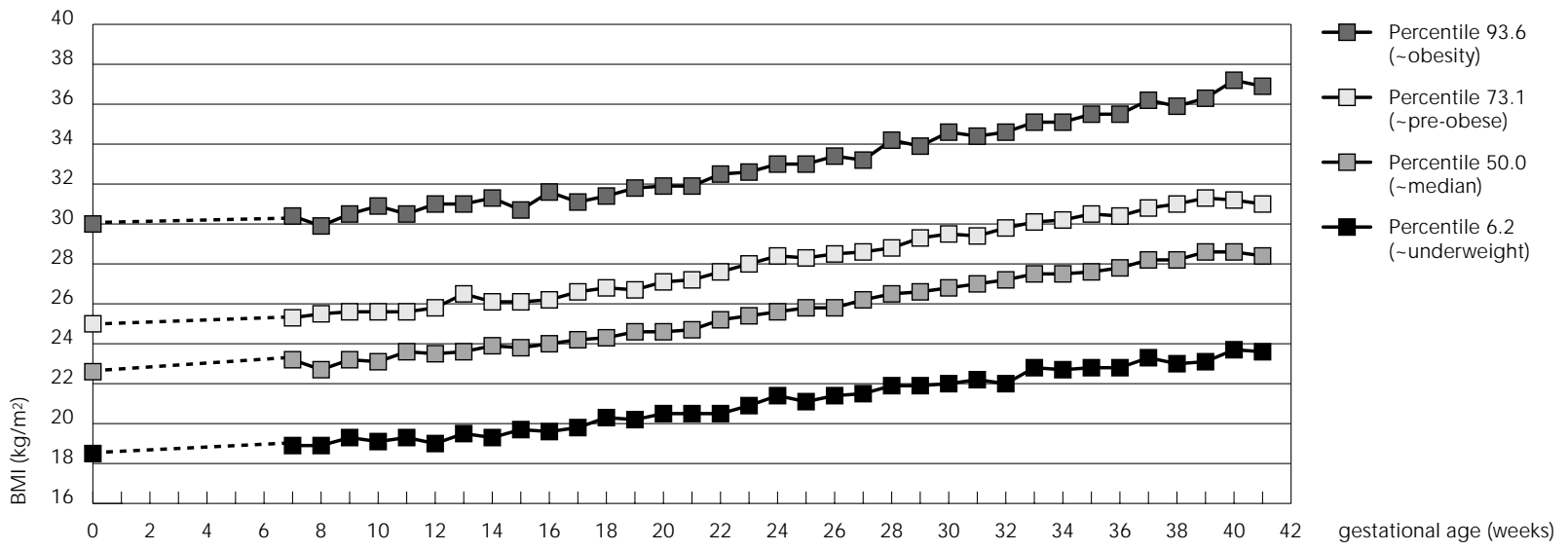

\begin{tabular}{lccccc}
\hline Body mass index $\left(\mathrm{kg} / \mathrm{m}^{2}\right)$ & \multicolumn{5}{c}{ Gestational age (weeks) } \\
& 14 & 20 & 24 & 28 & 32 \\
\hline Obese & 31.1 & 31.6 & 33.0 & 33.4 & 34.5 \\
Pre-obese & 26.1 & 27.1 & 28.4 & 28.8 & 29.8 \\
Underweight & 19.3 & 20.5 & 21.4 & 21.9 & 22.0 \\
\hline
\end{tabular}

(Siega-Riz et al., 1994). In this population, nearIy $17.4 \%$ of women were overweight, approximately $10.5 \%$ of these obese, and weight gain goals were also infrequently achieved (52\% of the overweight women). Another, more recent, U.S. study in low-income women showed even less achievement of weight gain goals: $68 \%$ of overweight and $52 \%$ of obese women gained in excess of the recommendations (Cosgwell et al., 1995).

The future health risks associated with the extremes of nutritional status during pregnancy and at birth are being increasingly recognized. Low birth weight, associated with being underweight prior to pregnancy and having inadequate weight gain during pregnancy, increases future risk of diabetes, hypertension, and cardiovascular disease (Barker et al., 1993; Hales et al., 1991; Phillips, 1998). On the other hand, obesity during pregnancy (Cnattingius et al., 1998; Faúndes et al., 1988) and excessive weight gain (IOM, 1990) are associated with an increase in morbidity both for the mother and the fetus (NIH/ NHLBI, 1998), including maternal weight retention (Scholl et al., 1995). Addi- tionally, excess birth weight appears to be associated with excess weight later in life (Charney et al., 1976). The impact of obesity and excessive weight gain during pregnancy on adult diseases is difficult to study, as obesity as currently present in women of childbearing age was a relatively infrequent finding until recently.

Limitations to our study should be noted. The lack of active follow-up and the accompanying inability to perform chart review on a large fraction of the women initially enrolled make our estimates less representative of the initial cohort. Due to the characteristics of study sample selection, our study sample cannot be considered directly representative of Brazilian pregnant women. However, comparisons of data on educational level, nutritional status and gestational age at delivery (IBGE, 1996) suggest that characteristics of our sample are comparable with those of pregnant women, at least in the large metropolitan areas of Brazil. An additional limitation is that 1st trimester weight gain, as it occurred prior to the study enrollment, relies on referred pre-pregnancy 
Mean ( \pm standard deviation) estimated total weight gain $(\mathrm{kg})$ according to pre-pregnancy Institute of Medicine weight status* among women aged 20 to 48, 1991 to 1995.

\begin{tabular}{|c|c|c|c|c|c|c|}
\hline \multirow[t]{2}{*}{ Trimesters } & \multicolumn{6}{|c|}{ Pre-pregnancy weight status } \\
\hline & Underweight & Normal & O verweight & Obesity & Total & $\mathrm{p}$ \\
\hline First $(n=3,354)$ & $3.8( \pm 4.8)$ & $2.4( \pm 4.7)$ & $1.9( \pm 5.6)$ & $1.2( \pm 5.8)$ & $2.5( \pm 5.0)$ & $<0.001$ \\
\hline Second $(n=3,247)$ & $6.1( \pm 3.7)$ & $6.3( \pm 3.5)$ & $5.8( \pm 4.3)$ & $4.2( \pm 4.1)$ & $6.0( \pm 3.7)$ & $<0.001$ \\
\hline Third $(n=3,063)$ & $4.8( \pm 3.8)$ & $4.9( \pm 3.4)$ & $4.7( \pm 4.1)$ & $4.4( \pm 4.0)$ & $4.8( \pm 3.6)$ & 0.1455 \\
\hline Second and third $(n=3,826)$ & $10.7( \pm 4.7)$ & $11.0( \pm 4.9)$ & $10.0( \pm 5.6)$ & $8.3( \pm 5.7)$ & $10.6( \pm 5.1)$ & $<0.001$ \\
\hline O verall $(n=3,082)$ & $14.2( \pm 5.5)$ & $13.0( \pm 5.7)$ & $11.5( \pm 6.5)$ & $9.2( \pm 8.4)$ & $12.7( \pm 6.2)$ & $<0.001$ \\
\hline Recommended by $10 \mathrm{M}$ & $12.5-18.0$ & $11.5-16.0$ & $7.0-11.5$ & $>6.8$ & & \\
\hline
\end{tabular}

* BMI cut points according to Institute of Medicine: underweight $<19.8 \mathrm{~kg} / \mathrm{m}^{2} ;$ overweight $>26.0 \mathrm{~kg} / \mathrm{m}^{2}$ and $<29 \mathrm{~kg} / \mathrm{m}^{2}$; and obese $>29.0 \mathrm{~kg} / \mathrm{m}^{2}$.

See text for formula definitions.

Table 3

Frequency of estimated weight gain less than, within, or more than the range recommended by the Institute of Medicine* according to pre-pregnancy weight statust.

\begin{tabular}{|c|c|c|c|c|c|c|}
\hline \multirow{3}{*}{ Pre-pregnancy weight status } & \multicolumn{6}{|c|}{ Weight gain } \\
\hline & \multicolumn{2}{|c|}{$\begin{array}{l}\text { Less than } \\
\text { recommended (\%) }\end{array}$} & \multicolumn{2}{|c|}{ Within recommendations (\%) } & \multicolumn{2}{|c|}{$\begin{array}{l}\text { More than } \\
\text { recommended (\%) }\end{array}$} \\
\hline & Delivery $\ddagger$ & 40 weeks§ & Delivery $\ddagger$ & 40 weeks§ & Delivery $\ddagger$ & 40 weeks§ \\
\hline Underweight $(n=479)$ & 40.3 & 37.3 & 38.8 & 39.4 & 20.9 & 23.3 \\
\hline Normal $(n=1,943)$ & 39.7 & 37.4 & 34.2 & 33.1 & 26.1 & 29.5 \\
\hline O verweight $(n=382)$ & 23.3 & 22.2 & 27.2 & 25.1 & 49.5 & 52.7 \\
\hline Obese $(n=278)$ & 40.3 & 38.1 & 21.9 & 22.8 & 37.8 & 39.2 \\
\hline All women $(n=3,082)$ & 37.8 & 35.6 & 32.9 & 32.1 & 29.2 & 32.3 \\
\hline
\end{tabular}

* Total weight gain recommended by Institute of Medicine: $12.5-18.0 \mathrm{~kg}$ for underweight, $11.5-16.0 \mathrm{~kg}$ for normal weight, $7.0-11.5$ for overweight and $>6.8$ for obese women.

† BMI cut points according to Institute of Medicine: underweight $<19.8 \mathrm{~kg} / \mathrm{m}^{2} ;$ overweight $>26.0 \mathrm{~kg} / \mathrm{m}^{2}$

and $<29 \mathrm{~kg} / \mathrm{m}^{2}$; and obese $>29.0 \mathrm{~kg} / \mathrm{m}^{2}$.

₹ Calculated up to delivery.

Extrapolated from delivery to complete 40 weeks.

$\mathrm{p}<0.001$, comparing frequencies in weight gain categories across pre-pregnancy nutritional categories

(evaluated separately when weight gain estimated to delivery and when estimated to 40 weeks of gestation).

weight, which is subject to recall bias. However, on the basis of our previous findings concerning weight recall for Brazilian women studied outside of pregnancy (Schmidt et al., 1993), we believe that this measurement bias is probably small.

In conclusion, in a population generally representative of women attending Brazilian public health clinics in major cities, the prevalence of pre-obesity and obesity prior to pregnancy was high, and approximately two-thirds of the women did not achieve the weight gain recommended by the Institute of Medicine. Given the increasing epidemic of obesity, and the increasing evidence that both low and high birth weights increase risk for chronic disease, more attention should be given, to the question of achieving adequate weight gain during pregnancy as well as to the development, implementation, and evaluation of effective strategies of weight management in pregnancy. 
References

AL-ISA, A., 1998. Body mass index and prevalence of obesity changes among Kuwaitis. European Journal of Clinical Nutrition, 51:743-749.

ALLISON, D. B.; EDLEN-NEZIN, L. \& CLAY-WILLIAMS, G., 1997. Obesity among African American women: Prevalence, consequences, causes, and developing research. Women's Health: Research on Gender, Behavior, and Policy, 3:243-274.

BARKER, D.; HALES, C.; FALL, C.; OSMOND, C.; PHIPPS, K. \& CLARK, P., 1993. Type 2 (non-insulin dependent) diabetes mellitus, hypertension and hyperlipidemia (syndrome $\mathrm{X}$ ): Relation to reduced fetal growth. Diabetologia, 36:62-67.

BENICIO, D. A.; MONTEIRO, C. A.; CONDE, W. \& POPKIN, B. M., 2000. Shifting obesity trends in Brazil. European Journal of Clinical Nutrition, 54:342-346.

CAPURRO, H.; KONICHEZKY, S.; FONSECA, D. \& CALDEIRO-BARCIA, R., 1978. A simplified method for diagnosis of gestational age in newborn infant. Journal of Pediatrics, 93:120-122.

CHARNEY, E.; CHAMBLEE, H.; MCBRIDE, M.; LYON, B. \& PRATT, R., 1976. Childhood antecedents of adult obesity. Do chubby infants become obese adults? New England Journal of Medicine, 295:6-9.

CNATTINGIUS, S.; BERGSTROM, R.; LIPWORTH, L. \& KRAMER, M. S., 1998. Prepregnancy weight and the risk of adverse pregnancy outcomes. New England Journal of Medicine, 338:147-152.

COGSWELL, M. E.; SERDULA, M. K.; HUNGERFORD, D.W. \& YIP, R., 1995. Gestational weight gain among average-weight and overweight women What is excessive? American Journal of Obstetrics and Gynecology, 172:705-712.

FAQUIM, L., 1999. Planos de saúde. Os dois lados da regulamentação. Recursos Humanos em Síntese, 27. Março/Abril 1999. 12 Agosto 2000 «ttp:// www.gestaoerh.com.br/artigos/legi_010.shtml>.

FAÚNDES, A.; PASSINI, R. J.; SILVA, J. L. P.; DIAZ, A. J.; SILVA, J. C. G. S. \& PINOTTI, J. A., 1988. Study of alternative means of maternal weight evaluation as predictors of birthweight. Revista Brasileira de Ginecologia e Obstetrícia, 10:199-204.

FLEGAL, K. M.; CARROLL, M. D.; KUCZMARSKI, R. J. \&JOHNSON, C. L., 1998. Overweight and obesity in the United States: Prevalence and trends, 19601994. International Journal of Obesity and Related Metabolic Disorders, 22:39-47.

FOREYT, J. P. \& POSTON II, W. S., 1998.Obesity: A never-ending cycle? International Journal of Fertility and Women's Medicine, 43:111-116.

GROL, M. E.; EIMERS, J. M.; ALBERTS, J. F.; BOUTER, L. M.; GERSTENBLUTH, I.; HALABI, Y.; VAN SONDEREN, E. \& VAN DEN HEUVEL, W. J., 1997. Alarmingly high prevalence of obesity in Curacao: Data from an interview survey stratified for socioeconomic status. International Journal of Obesity and Related Metabolic Disorders, 21:10021009.

HALES, C.; BARKER, D. \& CLARK, P., 1991. Fetal and infant growth and impaired glucose tolerance at age 64. BMJ, 303:1019-1022.

IBGE (Fundação Instituto Brasileiro de Geografia e Estatística), 1996. DATASUS. 5 August 2000 ঝttp:
// www.datasus.gov.br/tabnet/tabnet.htm>.

IOM (Institute of Medicine), 1990. Nutrition During Pregnancy. Washington, DC: Subcommittee on Nutritional Status and Weight Gain During Pregnancy/Subcommittee on Dietary Intake and Nutrient Supplements During Pregnancy/Committee on Nutritional Status During Pregnancy and Lactation/Food and Nutrition Board/ National Academy of Science.

MONTEIRO, C. A.; MONDINI, L.; MEDEIROS-DESOUZA, A. L. \& POPKIN, B. M., 1995. The nutritional transition in Brazil. European Journal of Clinical Nutrition, 49:105-113.

NIH (National Institutes of Health)/ NHLBI (National Heart, Lung, and Blood Institute), 1998. Clinical Guidelines on Identification, Evaluation, and Treatment of Overweight and Obesity in Adults The Evidence Report. 2 October 1998 ঝttp:// www.nhlbi.nih.gov/guidelines/obesity/ob_gdlns. htm>.

PHILLIPS, D., 1998. Birth weight and the future development of diabetes: A review of the evidence. $\mathrm{Di}$ abetes Care, 21/22:B150-B155.

ROSSO, P., 1985. A new chart to monitor weight gain during pregnancy. American Journal of Clinical Nutrition, 41:644-652.

ROZOWSKI, J. \& ARTEAGA, A., 1997. The problem of obesity and its shocking characteristics in Chile. Revista Medica deChile, 125:1217-1224.

SAS INSTITUTE, 1998. SAS/STAT U ser's Guide, Version 6, Fourth Edition, Volume 1-2. Cary: SASInstitute Inc.

SCHMIDT, M.; DUNCAN, B. \&TAVARES, M., 1993. Validity of self-reported weight - A study of urban Brazilian adults. Revista de Saúde Pública, 27: 271-276.

SCHOLL, T. O.; HEDIGER, M. L.; SCHALL, J. I.; ANCES, I. G. \& SMITH, W. K., 1995. Gestational weight gain, pregnancy outcome, and postpartum weight retention. Obstetrics \& Gynecology, 86:423-427.

SICHIERI, R.; COITINHO, D. C.; LEÃO, M. M.; RECINE, E. \& EVERHART, J. E., 1994. High temporal, geographic, and income variations in body mass index among adults in Brazil. America Journal of Public Health, 84:793-798.

SIEGA-RIZ, A. M.; ADAIR, L. S. \& HOBEL, C. J., 1994. Institute of Medicine maternal weight gain recommendations and pregnancy outcome in a predominantly Hispanic population. Obstetrics \& Gynecology, 84:565-573.

WHO (World Health Organization), 1998. Obesity Preventing and Managing the Global Epidemic. WHO Consultation on Obesity. Geneva: WHO. 